\title{
The Behavioral Ecology of Family Planning in Two Ethnic Groups in Northeast India
}

\author{
Donna L. Leonetti • Dilip C. Nath • \\ Natabar S. Hemam
}

Published online: 6 October 2007

(C) Springer Science + Business Media, LLC 2007

\section{Erratum to: Human Nature \\ DOI 10.1007/s12110-007-9010-4}

Correction: add the following acknowledgments:

Supported by the INDO-US Programme on Contraceptive and Reproductive Health Research sponsored by the Indian Ministry of Science and Technology and the U.S. National Institute for Child Health and Development; Family Health International; the Andrew W. Mellon Foundation; and the Center for Studies in Demography and Ecology, University of Washington. The cooperation of Bengali and Khasi participants is most gratefully appreciated. Thanks also to Lisa Rende Taylor and Mary Shenk.

The online version of the original article can be found at http://dx.doi.org/10.1007/s12110-007-9010-4.

\section{L. Leonetti $(\bowtie)$}

Department of Anthropology, University of Washington, Seattle, WA 98195-3100, USA

e-mail: leonetti@u.washington.edu

D. C. Nath

Gauhati University, Gauhati, India

\section{N. S. Hemam}

Indian Institute of Technology Guwahati, Gauhati, India 